\title{
SURFACE LASER-GLAZING OF PLASMA-SPRAYED THERMAL BARRIER COATINGS
}

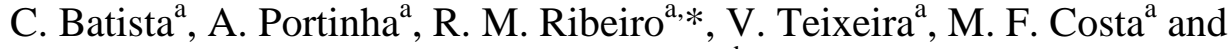 \\ C. R. Oliveira ${ }^{\mathrm{b}}$
}

a University of Minho, Physics Department, Campus de Gualtar, 4710-057 Braga, Portugal,

${ }^{\mathrm{b}}$ IDIT - Instituto de Desenvolvimento e Inovação Tecnológica, 4520-102 Santa Maria da

Feira, Portugal and University Lusíada, 4760-108 Vila Nova de Famalicão, Portugal

\begin{abstract}
Atmospheric plasma sprayed (APS) $\mathrm{ZrO}_{2}-8 \% \mathrm{WtY}_{2} \mathrm{O}_{3}$ thermal barrier coatings (TBCs)

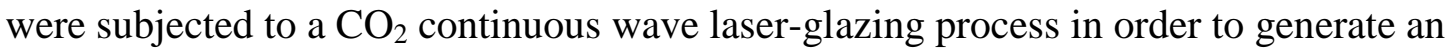
external dense layer produced by different processing parameters. For that purpose, different beam scanning speeds and track overlapping were chosen.

Surface roughness has been reduced significantly after laser-glazing. Despite the surface crack network, all laser-glazed specimens presented a fully dense and porous free external layer with a columnar microstructure. Surface cracks along the densified layer were found to have tendency to be oriented in two perpendicular directions, one in the direction of the laser beam travel, the other perpendicular to it. Moreover, the cracks parallel to the beam moving direction are found to be on the overlapping zone, coinciding with the edge of the subsequent track. The cracks along the densified layer are vertical and tend to branch and deviate from the vertical direction within the porous PS coating. The largest overlapping allied to the smallest amount of irradiated energy generated the most uniform layer with the shortest crack branches within the PS coating. For the as-sprayed coating, the XRD results revealed mainly t' non-transformable tetragonal zirconia with a small percentage of residual monoclinic zirconia. All glazed coatings presented only t' non-transformable tetragonal zirconia with some variations on preferable crystal orientation.
\end{abstract}




\section{Introduction}

Thermal barrier coatings (TBCs) are a demand in gas turbine engines for protection of the hot-section metallic components and to improve performance at high temperatures. Typical TBCs consist of a dual-layer system comprising an atmospheric plasma-sprayed (APS) ceramic (partially stabilized zirconia (PSZ)) top-coat over a metallic (MCrAlY where $\mathrm{M}$ is $\mathrm{Ni}$, Co or $\mathrm{Ni} / \mathrm{Co}$ ) bond-coat deposited by vacuum plasma spraying (VPS). The porous top-coat provides thermal insulation and the dense bond-coat not only reduces the mismatch of thermal expansion coefficients between the ceramic top-coat and metallic substrate (Ni-based superalloy) but also enables oxidation and hot corrosion protection, forming alumina as the principal protective scale (thermally grown oxide (TGO)).

Interconnected porosity and segmented crack networks introduced on plasma-sprayed TBCs due to volume reduction and residual stresses in the top coat [1-4] affect the mechanical properties and deteriorates the oxidation and corrosion resistance. These features are considered to be the path for corrosive gases and molten salts to attack the TBC system, especially in applications where low purity fuels are burned, and also support the infiltration of oxygen through the top coat leading to an increase in thickness of the TGO, favouring premature spallation.

Laser-glazing has been revealing a high potential for the improvement of plasma-sprayed TBCs properties by reducing surface roughness, sealing open porosity and generating a controlled segmented crack network. An increase of about fourfold in the lifetime of the plasma-sprayed TBCs in a $\mathrm{V}_{2} \mathrm{O}_{5}$ salt-containing corrosive environment was observed after laser-glazing [5], the same increase in lifetime was also seen in cyclic oxidation tests [6]. Recent studies [7] have shown that laser-glazing $\mathrm{ZrO}_{2}-8 \% \mathrm{WtY}_{2} \mathrm{O}_{3}$ coatings improved considerably microhardness, erosion and abrasion resistance, whilst lowered strength and stiffness. 
Segmented cracks, perpendicular to the surface along the densified layer are characteristic features of laser melted ceramic materials [4-18] and are generated by shrinkage and relief of thermal-induced stresses $[6,12,18]$. It was shown that these cracks, induced by laser treatment, improved thermal shock resistance by improving the strain accommodation. Moreover, a considerable reduction on the surface roughness leads to an improvement of the erosion resistance. On the other hand, densification and microstructural modification from lamellar to columnar can alter heat transfer by increasing thermal conductivity.

Also, the existence of macroscopic cracks may provide a fast path for oxygen and molten salts to attack the TBC system. For all this reasons, several studies have been carried out and are still underway to accomplish an affordable compromise between the desirable and undesirable properties.

In this work the effect of the laser-glazing process parameters on the morphology and microstructure of the $\mathrm{ZrO}_{2}-8 \% \mathrm{WtY}_{2} \mathrm{O}_{3}$ coatings is discussed. Thickness of the densified layer and distribution and size of characteristic laser-induced cracks are investigated. 


\section{Experimental details}

\subsection{Material}

The thermal barrier coatings used on this research consisted on an atmospheric plasma sprayed $\mathrm{ZrO} 2-8 \% \mathrm{Y}_{2} \mathrm{O}_{3}$ top coat deposited on a steel substrate, since this work is focused on the phenomena occurring within the top coat. Specimen preparation details are described elsewhere [19].

\subsection{Laser-glazing}

An industrial high power $(6.0 \mathrm{~kW}) \mathrm{CO}_{2}$ continuous wave laser (wavelength $10.6 \mu \mathrm{m}$ ) (Rofin-Sinar RS6000) with a 3-axis CNC workstation was used at a power of 500W to laserglaze coatings surface. Different scanning speeds (moving specimen), shown in Table 1, were set to apply different amounts of energy to each sample. The laser was operated in a $\mathrm{TEM}_{01 *}$ mode at the chosen power, and with the beam slightly defocused $\left(\mathrm{d}_{\text {spot }}=0.43 \mathrm{~mm}\right)$. Another sample was used before the final glazing process to generate a single track at each chosen scanning speed. The width of each track was then measured so the beam could be shifted away a sufficient distance for each parallel scan assuring a known overlap of tracks.

\subsection{Characterization}

Coatings microstructure and surface morphology were analyzed by optical and scanning electron microscopy (SEM). Cross-section planes, perpendicular to laser beam travel direction, were previously prepared metalographically for cross-section analysis. Freestanding coatings were prepared as well so they could be fractured and observed along through-thickness. Microtopography based in laser triangulation [20] has been used as well as a complementary technique to monitor coatings surface morphological changes. 
With the purpose of examining phase transformations of zirconia for the various laser treated specimens, an X-ray diffractometer using a continuous scan of $\mathrm{Cu} \mathrm{K}_{\alpha 1}$ radiation with $0.154056 \mathrm{~nm}$ wavelength (and $\mathrm{Cu} \mathrm{K}_{\alpha 2}$ with $0.154439 \mathrm{~nm} ; \mathrm{K}_{\alpha 2} / \mathrm{K}_{\alpha 1}=0.5$ ) was used to acquire the patterns within the $2 \theta$ range $20-80^{\circ}$ using a step size of $0.02^{\circ}$. 


\section{Results and Discussion}

\subsection{Surface morphology and microstructure}

From visual inspection, the coatings changed from a light gray to a soft yellow glassy transparent surface and spallation was not observed in any case. SEM studies shows that a network of cracks has formed in the coatings, the porosity was eliminated and the homogeneity has been improved. Some voids were found at the surface, located mostly over cracks, and were probably formed by release of gas in regions of higher porosity. By means of laser triangulation technique, surface topography was analysed and roughness $\left(R_{a}\right)$ has been determined for all specimens. Fig. 1 illustrates the contrast of surface morphology, before and after the laser treatment. Roughness results, shown in Table II, demonstrate a significant decrease after laser-glazing. Disparity in roughness values of glazed coatings are related to the different processing parameters. The roughness increased with the increase of crack density, as a consequence of the increase of beam scanning speed and overlap. However, specimen LG12 presents lower roughness than LG10 and LG7 due to a smoother surface caused by the large overlap of tracks.

The melted region, shown in Fig. 2, consists of a fully dense columnar microstructure differing significantly from the as-sprayed one. Microstructural inhomogeneities, such as unmelted/partially melted powder particles, pores and cavities, common to plasma-sprayed coatings, were eliminated. Despite the voids found at the surface, pores have not been found within or at the lower region of the melted layer. Although the molten pool has solidified rapidly as the laser beam moved way, there was time enough for pores, existing in the assprayed coating, to coalesce and rise to the surface.

Fig. 3 depicts a top view backscattered electron micrograph where it is recognizable a crack network. The cracks tend to be oriented in two perpendicular directions, one along the laser beam travel (vertical in micrographs), and the other perpendicular to it. The cracks 
oriented along the beam travel are spaced approximately the same distance (corresponding to the chosen track shift) coinciding with the edge of the subsequent track. The other cracks, perpendicular to the moving direction of the specimens are more dependent on the scanning speed, resulting in higher density of cracks with the increase of the scanning speed. The cracks are considered to be caused by shrinkage and relaxation of residual stresses during the cooling down of molten zirconia to room temperature $[6,12,18]$ and are probably formed by the large and localized temperature gradients which generates residual stresses after the laser has passed. When the laser scanning speed is increased, the higher is the thermal gradient and consequently the solidification is faster, resulting in higher thermal stresses and thus higher crack initiation.

Different layer profiles were achieved by varying the applied energy and track overlap (Fig. 4). In all cases, the cracks across the densified layer are perpendicular to the surface and start to branch and deviate from the vertical direction within the porous PS coating (Fig. 5). None of the coatings presented cracks extending to the interface between substrate and topcoat although LG5 seems to be quite damaged presenting very long cracks initiated at the overlapping region of the melted layer and extending across the PS coating to the centre of the tracks (Fig. 4a).

Coating LG12 (Fig. 4d) shows the most uniform melted layer. The largest overlapping allied to smallest amount of irradiated energy generated a very dense layer of uniform thickness. Comparatively to the others, it presents the higher amount of cracks, within the melted layer, regularly spaced but fewer and shorter branches across the plasma-sprayed coating.

For the different amounts of applied energy, track depths ranged from approximately 70 to $175 \mu \mathrm{m}$ and track widths from 1.01 to $1.21 \mathrm{~mm}$ (Table I). For the whole laser-glazed coatings, the melted layer maximum thickness is within the values for the respective single track depth 
except for the LG12 coating that presented a slightly higher value, $77 \mu \mathrm{m}$, due to the high overlap (more than half of its respective track width: $0.61 \mathrm{~mm}$ ).

\subsection{Phase transformation}

The achieved XRD spectra cover the $2 \theta$ range where the tetragonal, cubic and monoclinic main characteristic diffraction peaks of zirconia can be found. The $2 \theta$ range showed in Fig. 6 represents the range in which the most intense peaks of the monoclinic phase may appear depending on its presence. It is evident only for the as-sprayed coating the existence of monoclinic zirconia. The as-sprayed coating exhibits mainly t' non-transformable tetragonal phase and a small amount of residual monoclinic phase. Local inhomogeneities in $\mathrm{Y}_{2} \mathrm{O}_{3}$ content (deriving from the feeding-powder) were unable to homogenize during the rapid cooling inherent in the plasma spray process, and so, remained within the top coat.

All laser-glazed coatings present only t' non-transformable tetragonal phase, no monoclinic phase is detected. This can be explained by a homogenization, during melting, of the chemical composition of the two phases present in the as-sprayed coating. The cubic phase then formed, comprising the whole yttria content, transforms to the t' martensitic phase with the same composition by a diffusionless mechanism due to rapid cooling. Furthermore, detailed comparisons of the patterns on range $72-76^{\circ}$ (Fig. 7) showed that the calculated lattice parameters of the t' phase do not vary more than $0,2 \%$. It was also observed changes in the relative intensity of individual peaks induced by the glazing process. This is a result of preferable crystal orientation due to microstructural rearrangement of the melted zone. The splats lamellar structure, typical of plasma-sprayed coatings, changed to a columnar structure (Fig. 2). 


\section{Conclusions}

Plasma sprayed $\mathrm{ZrO}_{2}-8 \% \mathrm{WtY}_{2} \mathrm{O}_{3}$ thermal barrier coatings were subjected to a $\mathrm{CO}_{2}$ continuous wave laser-glazing process in order to generate an external dense layer produced by different processing parameters. A morphological and microstructural characterization was accomplished resulting on the following conclusions.

Laser-glazing plasma-sprayed coatings decreased surface roughness significantly. The melted layer has a fully dense columnar microstructure free from the microstructural inhomogeneities existing in the plasma-sprayed coatings. A crack network has formed at the surface and is extended across the whole thickness of the melted layer. Within the melted layer, cracks are perpendicular to the surface, bellow it, they tend to tilt within the porous plasma-sprayed coating. This surface crack network is extremely dependent on the laser scanning speed and track overlapping. The density of cracks oriented perpendicularly to the laser moving direction increase with the increase of the laser scanning speed. The cracks oriented along the beam travel are located at the overlapping zone, coinciding with the edge of the subsequent track.

Laser-glazing allowed the homogenization of local inhomogeneities in $\mathrm{Y}_{2} \mathrm{O}_{3}$ content and led to the disappearance of the residual monoclinic phase due to rapid cooling. Only the nontransformable t' phase is present within the melted layer with some variations on preferable crystal orientation. Specimen LG12 presents the most promising laser-glazed coating for the improvement of thermal cycling and hot corrosion resistance. 


\section{Acknowledgements}

This work is part of the research project POCTI/CTM/44590/2002, approved by Portuguese Foundation for Science and Technology (FCT) and POCTI and supported by the European Community Fund FEDER. 


\section{References}

1. V. Teixeira, M. Andritschky, W. Fischer, H.P. Buchkremer, D. Stöver, J. Mater. Proc. Technol. 92-93 (1999) 209-216.

2. V. Teixeira, M. Andritschky, W. Fischer, H.P. Buchkremer, D. Stöver, Surf. Coat. Technol. 120-121 (1999) 103-111.

3. M. Lugovy, V. Slyunyayev, V. Teixeira, Residual stress relaxation processes in thermal barrier coatings under tension at high temperatures, Surf. Coat. Technol. (2003), in press.

4. G. Antou, G. Montavon, F. Hlawka, A. Cornet, C. Coddet, F. Machi, Surf. Coat. Technol. 172 (2003) 279-290.

5. P.C. Tsai, C.S. Hsu, High temperature corrosion resistance and Microstructural evaluation of laser-glazed plasma-sprayed zirconia/MCrAlY thermal barrier coatings, Surf. Coat. Technol. (2003), in press.

6. H.L. Tsai, P.C. Tsai, Surf. Coat. Technol. 71 (1995) 53-59.

7. S. Ahmaniemi., P. Vuoristo, T. Mäntylä, Mater. Sci. Eng. A366 (2004) 175-182.

8. S. Ahmaniemi, M. Vippola, P. Vuoristo, T. Mäntylä, F. Cernuschi, L.Lutterotti, J. Europ. Ceram. Soc. 24 (2004) 2247-2258.

9. S. Ahmaniemi, P. Vuoristo, T. Mäntylä, Surf. Coat. Technol. 151-152 (2002) 412-417.

10. J. Lawrence, L. Li, Surf. Coat. Technol. 162 (2002) 93-100

11. J.F. Li, L. Li, F.H. Stott, Int. J. Heat Mass Transfer 47 (2004) 1159-1174.

12. S.O. Chwa, A. Ohmori, Surf. Coat. Technol.153 (2002) 304-312.

13. Z. Zhou, N.Eguchi, H. Shirasawa, and A. Ohmori, J. Therm. Spray Technol. 8(3) (1999) 405- 413

14. L. Pawlowski, J. Therm. Spray Technol. 8(2) (1999) 279-295.

15. A.H. Wang, W.Y. Wang, C.S. Xie, W.L. Song, D.W. Zeng, Appl. Surf. Sci. 221 (2004) 293-301

16. L. Bradley, L. Li, F.H. Stott, Mater. Sci. Eng. A278 (2000) 204-212.

17. L. Bradley, L. Li, F.H. Stott, Appl. Surf. Sci.138-139 (1999) 233-239.

18. Y. Fu, A.W. Batchelor, H. Xing, Y. Gu, Wear 210 (1997) 157-164.

19. A. Portinha, V. Teixeira, J. Martins, M.F. Costa, R. Vaßen, D. Stöver, Advanced Research Workshop on Nanomaterials and Coatings, Kiev, NATO series E-Appl Sci., Kluwer Acad. Publ., 2002.

20. M.F.M. Costa, Opt. Eng. 35(9) (1996) 2743-2747. 
Tables

Table I: Varied parameters and resultant conditions of the laser-glazing process.

\begin{tabular}{ccccccc}
\hline Specimen & $\begin{array}{c}\text { Scanning }_{\text {speed }^{\mathrm{a}}} \\
(\mathrm{mm} / \mathrm{min})\end{array}$ & $\begin{array}{c}\text { Track shift }^{\mathrm{a}} \\
(\mathrm{mm})\end{array}$ & $\begin{array}{c}\text { Overlap }^{\mathrm{b}} \\
(\mathrm{mm})\end{array}$ & $\begin{array}{c}\text { Energy } \\
\text { density }^{\mathrm{b}} \\
\left(\mathrm{J} / \mathrm{mm}^{2}\right)\end{array}$ & $\begin{array}{c}\text { Track }^{2} \\
\text { width }^{\mathrm{c}} \\
(\mathrm{mm})\end{array}$ & $\begin{array}{c}\text { Track }^{\mathrm{m}} \\
\text { depth }^{\mathrm{c}} \\
(\mu \mathrm{m})\end{array}$ \\
\hline LG5 & 5000 & 1 & 0.21 & 14.0 & 1.21 & 176 \\
LG7 & 7000 & 0.7 & 0.40 & 10.0 & 1.10 & 129 \\
LG10 & 10000 & 0.5 & 0.56 & 7.0 & 1.06 & 87 \\
LG12 & 12000 & 0.4 & 0.61 & 5.8 & 1.01 & 69 \\
\hline
\end{tabular}

${ }^{\mathrm{a}}$ Chosen parameters

${ }^{\mathrm{b}}$ Calculated values

${ }^{\mathrm{c}}$ Measured values

Table II: Microtopographic results of surface roughness.

\begin{tabular}{cc}
\hline Specimen & $\mathrm{R}_{\mathrm{a}}(\mu \mathrm{m})$ \\
& (Average roughness) \\
\hline As-sprayed & 14,67 \\
LG5 & 2,70 \\
LG7 & 7,85 \\
LG10 & 8,36 \\
LG12 & 5,58 \\
\hline
\end{tabular}




\section{Figure captions}

Fig. 1. Micrograph illustrating the contrast of surface morphology, before (left) and after (right) laser treatment.

Fig. 2. Fracture plane illustrating the columnar microstructure of the laser melted layer over the plasma-sprayed coating.

Fig. 3. Representative backscattered electron micrograph of the surface of a glazed coating illustrating crack distribution.

Fig. 4. Cross-section backscattered electron micrographs of the plane perpendicular to the beam travel direction illustrating the various layer profiles and segmented cracks of the different coatings; (a) LG5, (b) LG7, (c) LG10, (d) LG12.

Fig. 5. SE Micrograph illustrating crack profile. Within the melted layer, the segmented crack is perpendicular to the surface, bellow it, the crack tend to deviate from the vertical direction, along the porous PS coating.

Fig 6. XRD spectra in the low $2 \theta$ range; (a) as-sprayed, (b) LG5, (c) LG7, (d) LG10, (e) LG12.

Fig 7. XRD spectra in the high $2 \theta$ range; (a) as-sprayed, (b) LG5, (c) LG7, (d) LG10, (e) LG12. 


\section{Figures}

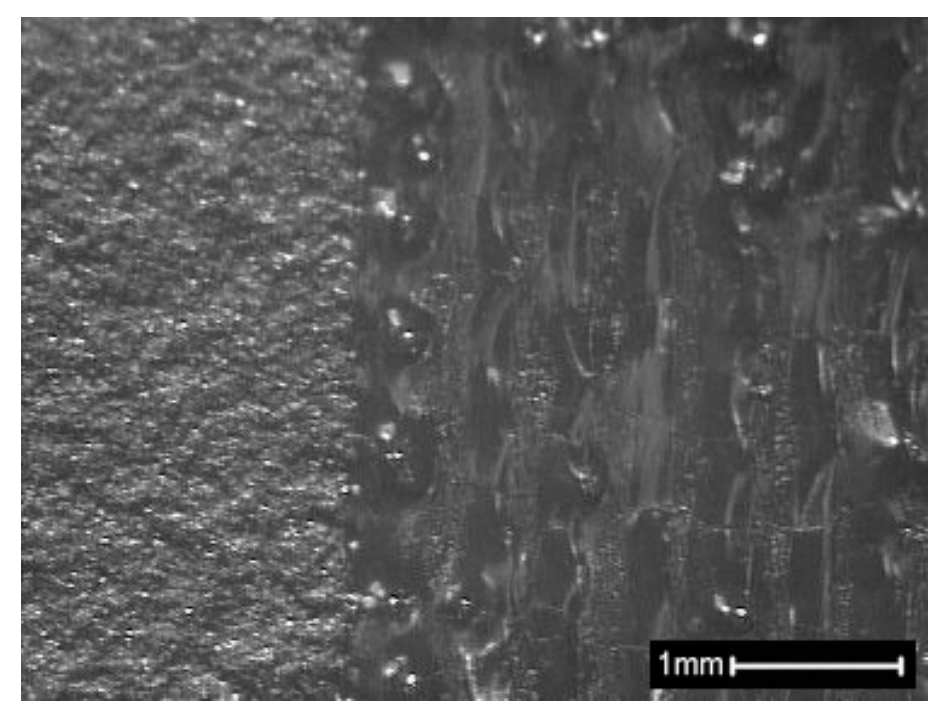

Fig. 1

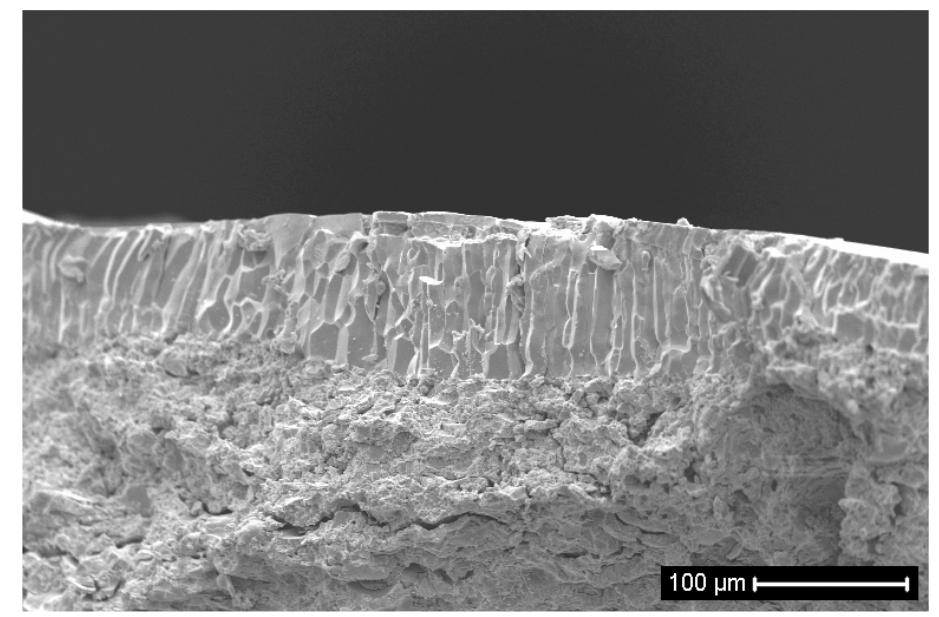

Fig. 2

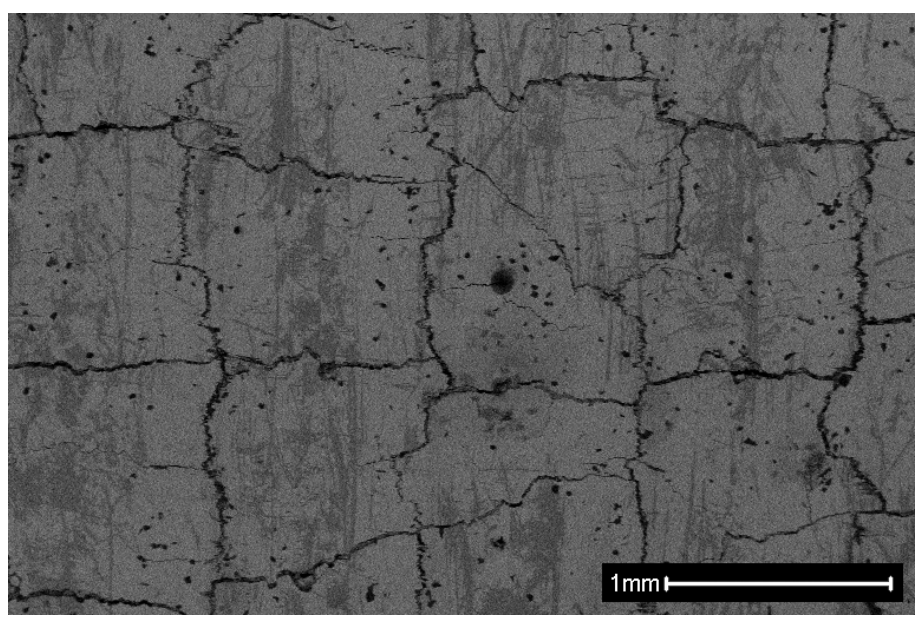

Fig. 3 


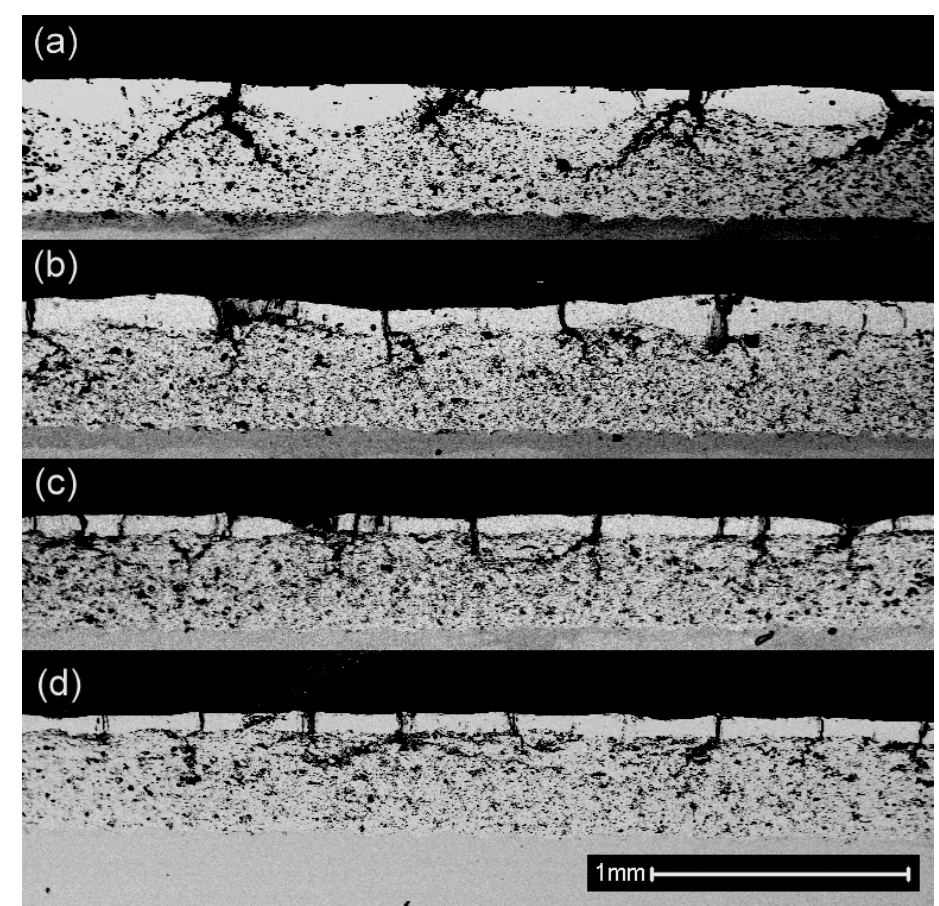

Fig. 4

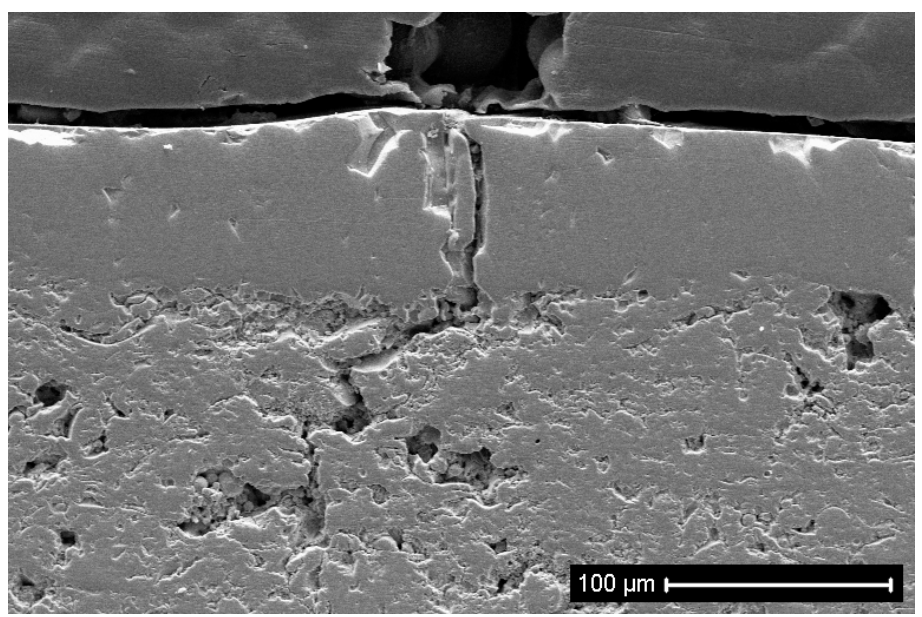

Fig. 5 


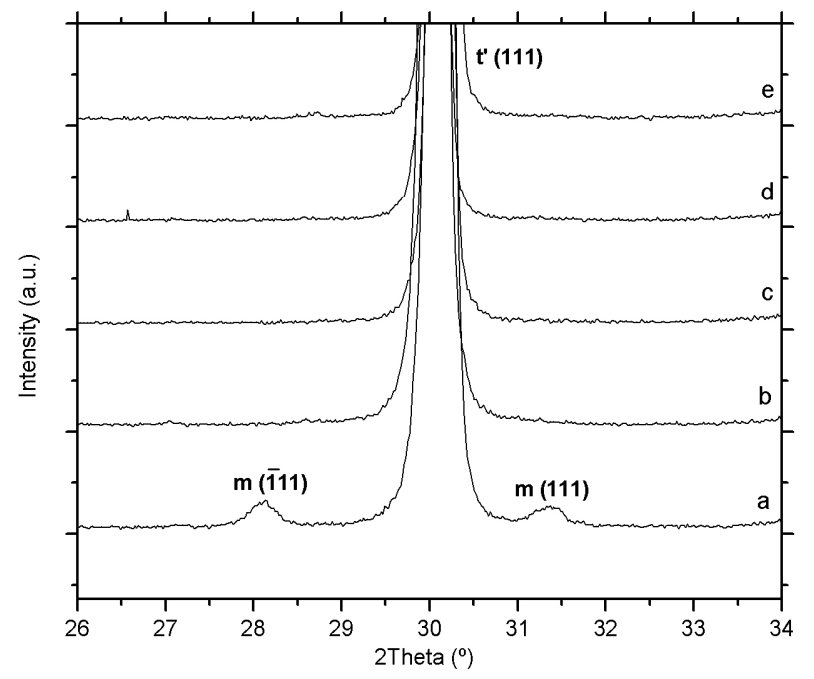

Fig. 6

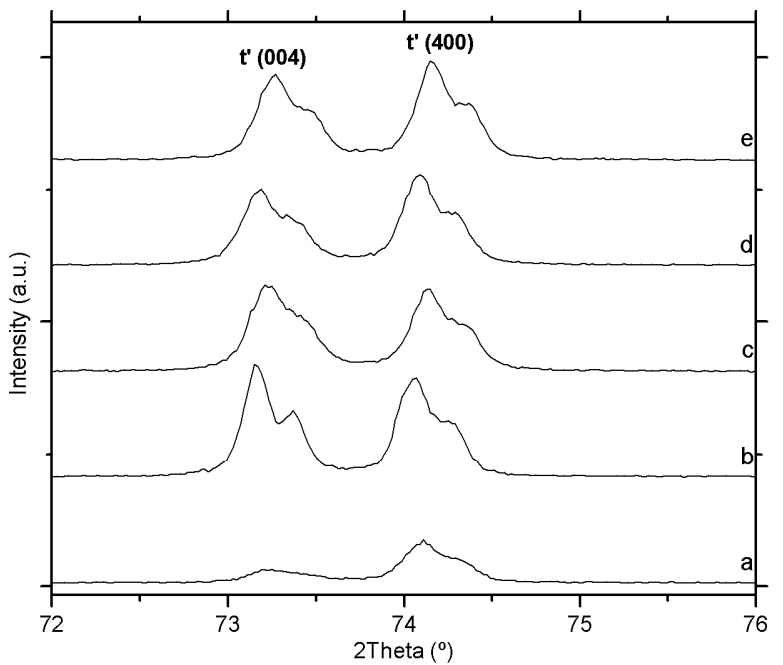

Fig. 7 